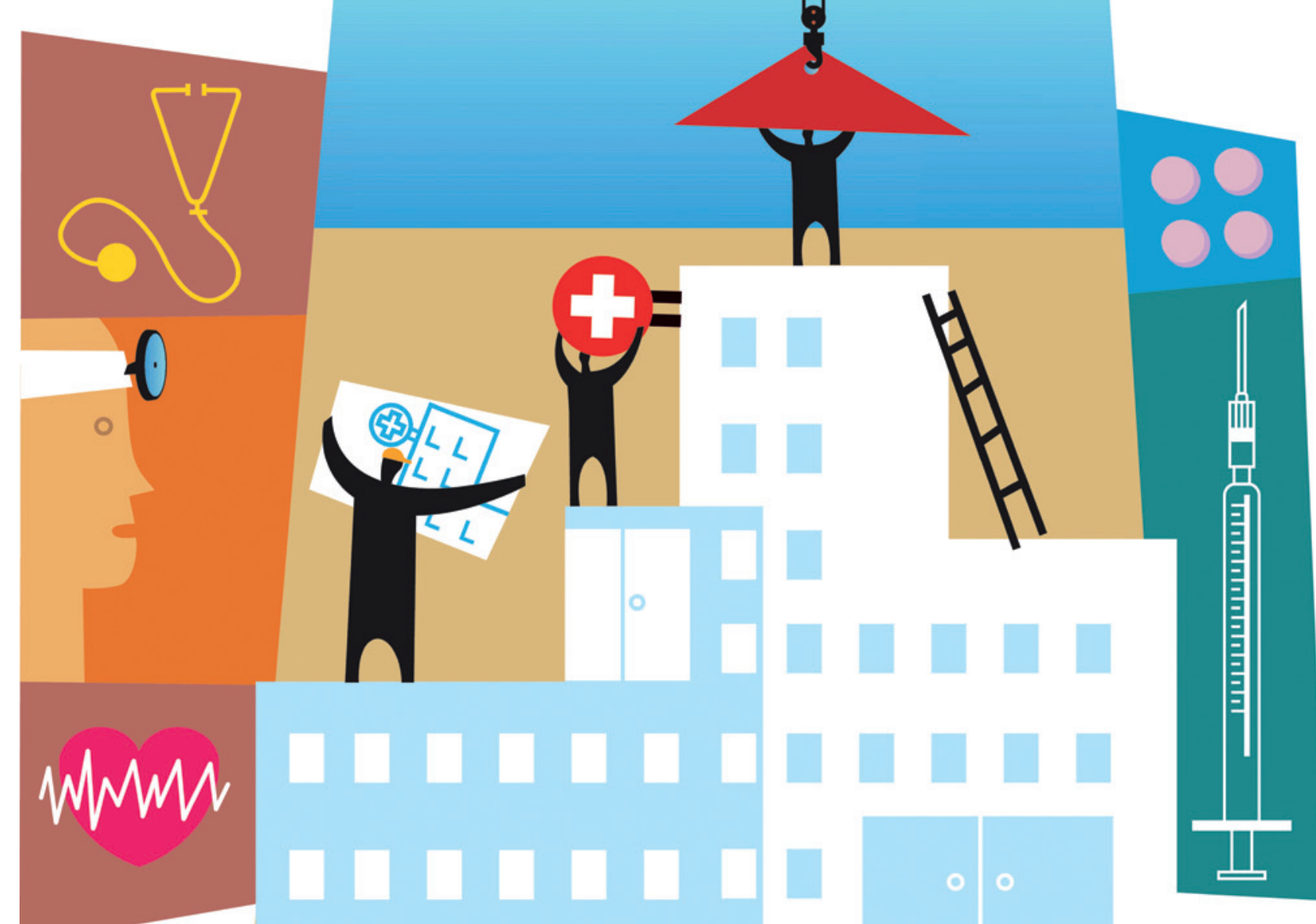

\section{Gestión de la Inversión Pública en Salud a la UTI} Oe

Por Carlos J. García* $y$ Felipe López $S^{* * *}$

*Profesor de Economía, Universidad Alberto Hurtado.

*Estudiante de Ingenieria Con
versidad Alberto Hurtado.
El uso de concesiones es una de las gran- tiago, cuya carga financiera para el Estades politicas subsidiarias que los gobiernos do ha aumentado constantemente desde de la concertación diseñaron para ofrecer su implementación y hasta el día de hoy ciertos bienes públicos como el transporte, sigue con serios problemas para satisfacarreteras, cárceles, puertos, aeropuertos cer de manera adecuada la demanda por y construcción de hospitales. Esta politica transporte en Santiago. Además, pese a la de la inversión y el mantenimiento de di- tema de concesión vaya a ser reempezado chos bienes por un determinado periodo de por un sistema $100 \%$ estatal o se pretend tiempo, a cambio de subsidios del Estado o volver al sistema antiguo, 100\% privado. pagos directos de los consumidores, como Pero, la suerte corrida por el sistema de pagos de col cas de las carreteras, cono El modelo de concesiones ha tenido resultados dispares. Sin hacer un análisis detallado de cada experiencia nos encontramos ejemplos de éxitos y fracasos: Casos positivos son el de las carceles concesionadas que han reducido los niveles de hacinamiento a través del aumento de los metros cuadrados de infraestructura carcelaria. De mismo modo, las autopistas urbanas han tos de las conexiones de distintos puntonte incremento del parque automotriz. Por el contrario, un caso complejo es el del sistema de transporte público Transan- carga financiera para el Estado y excesivos plazos de construcción de hospitales'. Crítico en este analisis fue la protesta de los funcionarios del Hospital Salvador el 2014 blecimiento. Entre los principales estrasos generados con este sistema se encuentran importantes hospitales (en términos de números de cama destacan): Alto Hospicio $(235$ camas), San Antonio (212 camas) Angol (234 camas) y Padre Las Casas (232 camas). Todos ubicados en ciudades con urgentes necesidades económicas.

Esto último más los magros resultados del sistema de concesiones llevó a que la Comisión Investigadora de las Eventuales Irregularidades en los Procesos de Inversión Publica en Infraestructura Hospitalaria elagularidades en las cuales estaban envuelto los procesos de inversión en infraestructura hospitalaria. El informe concluyó lapidariamente en contra del sistema de concesion en el sector salud: "el mecanismo de concesiones no resulta necesarlamente más construcción y puesta en jor plazos en fraestructura hospitalari requerida ta que puede ser construida por via sectorial"'

Como resultado el gobierno lanzó un bicioso programa de inversiones por $\$ 4000$ millones de dólares para el período 2014-18 Estos recursos permitirian al gobierno dar inicio a la licitación del diseño y estudios arquitectónicos de 20 hospitales, más 20 que se encontrarian en construcción y 27 que serian terminados (llamado originalmente programa 20-20-20, luego se adicionaron 7 hospitales mas), aportando estos últimos 2.466 camas hospitalarias. Esta inversión está a cargo mayoritarianente de IMINSAL y marginalmente del NOP. Para ilustrar de inversión pasaron de \$275 MM e 2014 $\$ 529 \mathrm{MM}$ (prácticamente el doble). Este mento presupuestario debiera además permitir la construcción de 37 Centros de Salud Familiar, 50 Centros Comunitarios de Salud Familiar, 38 nuevos Servicios de Atención Primaria de Urgencia de Alta Resolución (SAR), 10 Servicios de Atención Médica de Urgencia, por nombrar algunos.

A pesar del considerable aumento de los aportes fiscales para inversion hospitalari el monto ejeculado a mayo del presente año ha sido sólo de \$38 MM, apenas 7,2\%
Gráfico 1: Construcción de Hospitales Públicos

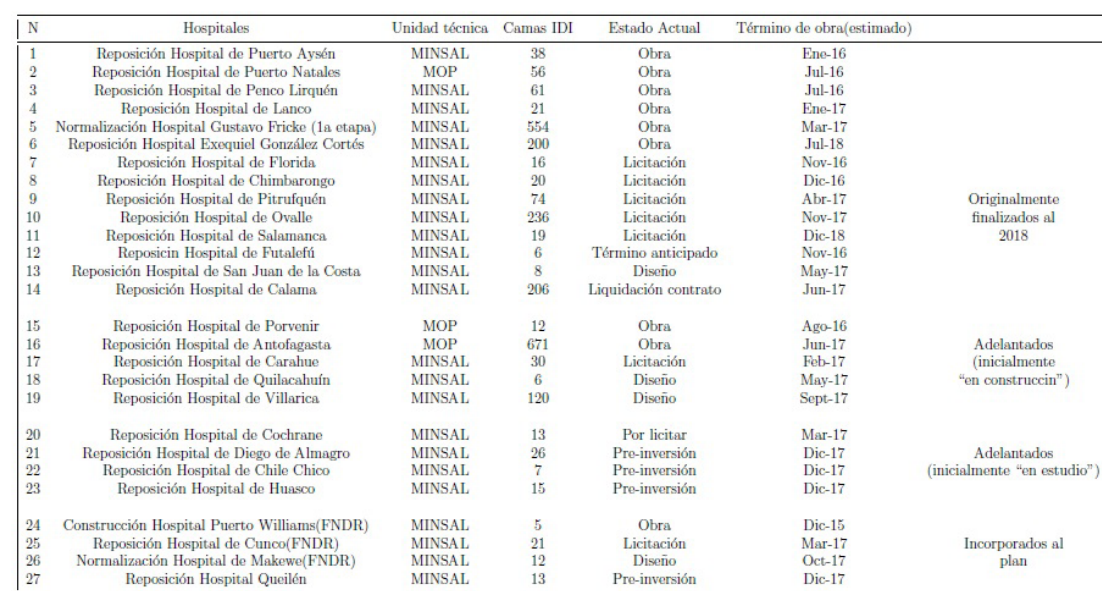

Fuente: MINSAL

del presupuesto total en inversiones. S miramos el presupuesto de inversión ejecutado a mayo del 2014, corresponde a un aproximado del total. Según información entregada por la Ministra de Salud, de los 27 hospitales que se deben construir solo 9 están en obra, aportando con 1000 camas aunque la mitad estarán recién disponibles en 2017. El resto de los hospitales están en etapa de diseño y licitación, indicando el atraso de las obras de inversión. En resumen, el aumento efectivo de camas sera efectiva solo a fines del 2018, considediendo la inversión en el sector.

El retraso en las inversiones en el sector salud y por ende la falta de camas es critico. Según datos del Banco Mundial ${ }^{3}$ el crecimiento poblacional en 2014 fue de 0,9\% lo que en literatura demográfica se señala cono "transión demografica en etapa ción. Esto aumenta el número de usuarios de las redes públicas de salud compuesto mas sobre la inadecuada oferta de salud publica en los años que vienen. En especia porque las enfermedades de este sector de a población son costosas e intensivas en uso hospitalario (diferentes tipos de cáncer,
enfermedades coronarias, diabetes etc) Al atraso de las inversiones en el sector, se suma la situación financiera de los hospitales públicos del pais. Una de las principales estudio de Cid y Bastías publicado en $2014^{4}$ es que la estructura de precios no refleja los costos efectivos en los procedimientos. As (S) 政 itiva, se requere cambitiaria. En def-

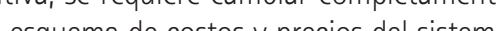
úblico con el fin de que los costos sean tamente cubiertos.

Dado estos hechos resulta válido preguntarse siel pais necesitaba terminar con sistema de concesiones en el sector saud o más bien la política correcta era un reforma sustancial al sistema. Todavía es pematuro sacar conclusiones definitivas pro es evidente que el mejoramiento de sector salud no pasa solo por terminar con a a

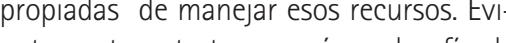
perim pión en los pox pas me actual administecion en los proximos meses pues debera mostrar que el Estado puede gestionar fraestructura hospitalaria.

http:/|ldesconcierto.cl/concesiones-hospitalarias-el-a

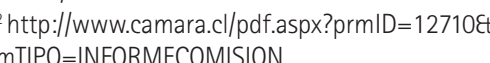
GROW//countries "http://www.scielo.cl/pdf//mc/v142n2/art03.pdf 